\title{
Mitigation of Delays Attributable to the Contractors in the Construction Industry of Sri Lanka - Consultants' Perspective
}

\author{
D. A. R. Dolage and T. Pathmarajah
}

\begin{abstract}
This study focuses on determining important causes of construction delays attributable to contractors in large construction projects in Sri Lanka and the degree of severity of these causes. The causes of delay have been found based on the perceptions of the engineers working for three state affiliated establishments namely, Department of Buildings (BD), Road Development Authority (RDA) \& National Water Supply and Drainage Board (NWSDB).The severity of each cause of delay is measured and represented through a severity index (SI). The causes of delay were determined and ranked in the descending order of severity. According to the findings, Poor project planning $\mathcal{E}$ scheduling (SI -82.54) is the most influencing factor causing delays in construction projects. In the descending order of severity, the other causes of delay are Low profit margin (SI -80.28), Inadequate cash flow management (SI -78.31), Handling of too many project sat a given time (SI -75.21), and Incompetence of the key staff (SI -74.93).Spearman rank correlation coefficient was used to determine the degree of agreement on the ranking of severity of causes of delay among the organisations. The highest degree of agreement is between $B D$ ENWSDB (0.77). There exists an intermediate degree of agreement between $R D A \mathcal{E} N W S D B(0.73)$ and the lowest is between $R D A \& B D(0.70)$. The study finally makes 10 recommendations to mitigate construction delays.
\end{abstract}

Keywords: Construction delays, Construction industry, Causes of delay

\section{Introduction}

Delay in completing construction projects is rampant across the world. They are invariably accompanied by cost and time overruns. Naturally, construction project delays have undesirable effects on smooth functioning of projects, such as adversarial relationships among project participants, distrust, litigation, arbitration and cash-flow problems. Construction projects often get abandoned or terminated due to the construction delays. If the contractors follow systematic contractual procedures and proper project management, the project delays can be minimised. Construction delays can be minimised only when the causes of delay are identified and countermeasures are taken.

Time management of a project is usually an important requirement for both the owner and the contractor of a particular project. Although the inaction of the client and the consultant and other factors such as unfavourable government policies and 'acts of God' also contribute to the overall construction delays. The previous studies reveal that project delays are mainly due to non completion of projects on time by the contractor.

A vast majority of major construction projects carried out in Sri Lanka are funded through foreign loans which entail payments of interest. When a project is delayed, it incurs costs by having to pay for additional salaries for staff and escalated material prices due to inflation. Hence, if delays are contained, profits could be increased, which can be utilised by the contractor for their business development and economic growth for the country. Therefore, the study aims to identify the major causes of construction delays attributable to the

Eng. (Dr.) D. A. R. Dolage, CEng, FIE(Sri Lanka), BScEng. (Moratuwa), MSc (Reading), MA (Colombo), MBA (SJP), DBA (UniSA), Senior Lecturer, Department of Civil Engineering, The Open University of Sri Lanka.

Eng. T. Pathmarajah, CEng, MIE(Sri Lanka), BSc Eng. (Peradeniya), MTech (OUSL), Chief Engineer, Road Development Authority, Sri Lanka. 
contractors in Sri Lanka and the ways of mitigating delays in construction projects.

The main objectives of this study are;

1. To identify and rank the causes of delays attributable to contractors in the construction industry of Sri Lanka.

2. To assess the degree of agreement of rankings of causes of delays among state sector construction organisations.

3. To make recommendations to prevent or mitigate construction delays based on the analysis of its significant causes.

\section{Literature Review}

\subsection{Causes of Construction Delays}

A plethora of both local and international research studies conducted on causes of delays in construction projects were reviewed. Evidently, no study has been carried out to examine the delays attributable to the contractors in Sri Lanka, hence there is a potential research gap. Although similar studies have been carried out in other countries, a study devoted to examine the same aspect in the local context is of great importance. This is because of the differences in economic policies, project characteristics, practical problems and resource availability of Sri Lanka in comparison to other countries.

Chan and Kumaraswamy (1998) conducted a study to evaluate the relative importance of 83 potential delay factors associated with construction projects in Hong Kong and found five critical delay factors, namely: poor risk management and supervision, unforeseen site conditions, slow decision making, client-initiated variations, and work variations.

A study was conducted by Jayawardane and Pandita (2003) on the topic of evaluating and mitigating the factors affecting construction delays. According to this study, both contractors and consultants have collectively ranked rainy weather, manpower skill and material shortage as the top ranking causes of construction delays. In order to minimise such delays, the study recommends the following; proper construction planning, cash flow management, human resource development and further training in specialised skills, frequent site meetings and joint site inspections.

A study was conducted by Pathiranage and Halwatura (2010) to identify the factors influencing the duration of road construction projects in Sri Lanka and propose ways to mitigate delays. This study found that the local road construction projects have experienced from 56 to 88 percent of average time overrun compared to the original (planned) project duration. According to the study, project financing by the client and the cash flow problems of the contractor is the most significant factor causing construction delays. A recent study by Dolage and Rathnamali (2013), revealed the most significant factors causing time overrun, as per the perceptions of all involved parties, are; 'rainy weather', 'poor liquidity of the contractor' and 'inaccurate planning and scheduling of projects.

\subsection{Methodological Approaches}

Most of the previous researchers have adopted questionnaire survey methods to obtain answers to the research questions. The questionnaires have been designed to evaluate the significance of causes for delays in project completion, based on the perceptions of respondents. Pathiranage and Halwatura (2010) identified the factors causing construction delays from the literature and from a pilot survey in which the participants were experienced highway specialists in Sri Lanka. In this study, a questionnaire was developed to assess the perception of contractors on the percentage delay and the relative significance index of factors influencing the duration of road construction projects in Sri Lanka.

Dolage and Perera (2009) carried out a study on delays in the pre-construction phase of state sector building projects by adopting a questionnaire survey to evaluate the perceptions of respondents of causes of delay. Prior to the distribution of the questionnaire, interviews were conducted with four consultants, three clients and three contractors to identify the factors causing delays in the 
pre-construction stage. Based on the outcome of these interviews, a questionnaire was developed to assess the perceptions of the respondents. The relative importance of various causes of delay was measured using relative importance index.

\subsection{Research Gap}

Most of the previous studies have analysed the overall project delays caused by the responsible parties with generic delays such as excusable or non excusable construction delays without considering the contract value.

In a study on construction delays, carried out in Florida, Ahamed (2003) shows that different parties are responsible for the overall project delay as follows; Contractor $44 \%$, Owner $24 \%$, Government $14 \%$, Shared (between owner \& consultant) $12 \%$ and Consultant $6 \%$.

A study carried out on delays in public utility projects of Saudi Arabia by Khalil (1999), shows that different parties are responsible for the overall project delay in the following manner; Contractor $44 \%$, Owner $22 \%$, Consultant $14 \%$ and others $20 \%$.

According to Pathiranage and Halwatura (2010), the contractor is the most responsible party for road construction delays in Sri Lanka of all the parties involved. The study also reveals the responsibility of the client is perceived to be more important than that of the consultant. However, no attempt has been made to examine contractor's contribution to delays in major construction projects, and proposes mitigative measures for construction delays in Sri Lanka.

\section{Methodology}

\subsection{Classification of causes of delay}

The causes of construction delays could vary from country to country because of the differences in political, economic, social, and environmental conditions, and government regulations. In previous studies, different researchers have examined construction project delays from a different perspective and identified a number of different causes of delay. From these studies and the interviews that the authors conducted with engineers experienced in project execution, 24 potential causes of delay were identified. The pertinence of these causes were verified through senior engineers, involved in the construction projects implemented by three government owned, major infrastructure construction organisations; $\mathrm{BD}, \mathrm{RDA}$ and NWSDB.

The selected causes were classified into three main categories, namely, management related causes, finance related causes and construction related causes, based on the origin, as follows:

\section{Management Related Causes (MRC)}

1. Poor project planning \& scheduling

2. Incompetence of key staff

3. Poor decision making by management

4. Poor coordination with sub contractors

5. Poor coordination among staff

6. Delays in material supply

7. Disputes with other parties

8. Internal organisational problems

9. Poor skill development

10. Fraudulent practices in the organisation

\section{Finance Related Causes (FRC)}

1. Low profit margin

2. Inadequate cash flow management

3. Inefficiency in billing and collecting payments

4. Poor estimation practices

5. Inadequate progress reviews

6. Poor cost controlling system

\section{Construction Related Causes (CRC)}

1. Handling of too many projects at a given time

2. Faulty work

3. Poor communication with other parties

4. Insufficient quality control

5. Poor supervision of work

6. Insufficient availability of equipment

7. Unqualified workforce

8. Insufficient safety precautions at site

\subsection{Collection of data}

The knowledge required for this research came from review of literature, professional experience of the authors and interviews with the experts. The primary data was obtained through a questionnaire which was distributed to engineers attached to BD, RDA and NWSDB. The questionnaires were filled by the heads of divisions or senior engineers 
of large projects. The respondents were asked to indicate the relative importance of each cause of delay on a five-point Likert scale; the points are: Strongly disagree -1, Disagree -2, Neutral -3, Agree -4 and Strongly agree -5 .

The selected state organisations for the study have different organisational setups. The RDA is an authority dealing with construction and maintenance of large scale projects associated with A and B Class roads, airports, expressways and large bridges. The NWSDB is a statutory board concerned with construction and maintenance of major water treatment plants, sewage plants, supply lines, and water towers, while the $\mathrm{BD}$ is a state department dedicated to handling state sector building requirements.

\subsection{Approach to Data Analysis}

Each cause of delay has a corresponding severity index which is computed using the following equation:

Severity Index $(\mathrm{SI})=\sum^{\mathrm{a}} \mathbf{i} \mathrm{x}_{\mathbf{i}}$

Where: $\mathrm{i}=1,2,3,4,5$

$a_{1}=1 / 5$ for 'Strongly disagree', $a_{2}=2 / 5$ for 'Disagree', $\mathrm{a}_{3}=3 / 5$ for 'Neutral', $\mathrm{a}_{4}=4 / 5$ for 'Agree' and $a_{5}=5 / 5$ for ' Strongly agree'

$x_{i}$ is the variable expressing the percentage of frequency for the $\mathrm{i}^{\text {th }}$ response.

Spearman's rank correlation coefficient is used to measure the degree of agreement on the severity of causes of delay between responses of any two organisations. The rank correlation coefficient is calculated using the formula:

$r=1-\left(6 \sum d^{2}\right) /\left(n^{3}-n\right)$

Where $\mathrm{r}$ is the Spearman rank correlation coefficient between two parties, $d$ is the difference between the ranks assigned to a given cause of delay, and $\mathrm{n}$ is the number of pairs of the variables. Using the ranking of causes of construction delays for the individual organisations, the agreement on ranking between organisations was evaluated.

\section{Results and Discussion}

\subsection{Severity indices}

The severity index of each cause of delay was computed with respect to each organisation, and presented in Table 1. As per Table 1, the top ten factors causing delays in construction projects, in the descending order of significance are as follows: Poor project planning \& scheduling (SI - 82.54),Low profit margin (SI - 80.28), Inadequate cash flow management (SI - 78.31),Handling of too many projects at a given time (SI - 75.21), Incompetence of key staff (SI - 74.93), Poor decision making by management (SI 74.08),Insufficient quality control (SI - 74.08), Insufficient availability of equipment (SI 73.24), Poor supervision of work(SI - 72.11) and Delays in material supply (SI - 71.83). Figure 1 shows the severity indices of causes of delay with respect to individual organisations and when the responses of all three organisations are combined.

\subsection{Spearman Rank Correlation Coefficient}

The Spearman correlation coefficients between organisations were computed to determine the degree of agreement on ranking and presented in Figure 2. There is a high degree of agreement between BD \& NWSDB (0.77), RDA \& NWSDB (0.73) and RDA \& BD (0.70).

The degree of agreement in the ranking of factors between two organisations can vary owing to the variation of scope of work, nature and value of projects and the setup of the organisations. In general, the projects handled by the NWSDB and the BD are almost similar in terms of scope of work, worksite administration, value of the project and use of materials. But the nature of the projects executed by the RDA is different from 
Table 1 - Severity indices of causes of delay based on perceptions of respondents

\begin{tabular}{|c|l|c|c|c|c|}
\hline \multirow{2}{*}{ Causes of delay } & \multicolumn{4}{|c|}{ Severity Indices } \\
\cline { 3 - 5 } & RDA & NWSDB & BD & All \\
\hline 1 & Poor project planning \& scheduling & 79.26 & 85.64 & 83.16 & 82.54 \\
\hline 2 & Low profit margin & 79.26 & 76.82 & 86.32 & 80.28 \\
\hline 3 & Inadequate cash flow management & 77.04 & 79.27 & 78.95 & 78.31 \\
\hline 4 & Handling of too many projects at a given time & 73.33 & 72.83 & 81.05 & 75.21 \\
\hline 5 & Incompetence of key staff & 71.85 & 75.24 & 78.95 & 74.93 \\
\hline 6 & Poor decision making by management & 71.11 & 75.24 & 76.84 & 74.08 \\
\hline 7 & Insufficient quality control & 77.04 & 70.43 & 74.74 & 74.08 \\
\hline 8 & Insufficient availability of equipment & 71.85 & 76.82 & 70.53 & 73.24 \\
\hline 9 & Poor supervision of work & 69.63 & 75.24 & 71.58 & 72.11 \\
\hline 10 & Delays in material supply & 68.15 & 73.65 & 74.74 & 71.83 \\
\hline 11 & Inadequate progress review & 73.33 & 68.14 & 71.58 & 70.99 \\
\hline 12 & Faulty work & 67.41 & 72.15 & 74.74 & 70.99 \\
\hline 13 & Poor coordination with sub-contractors & 69.63 & 72.15 & 70.53 & 70.70 \\
\hline 14 & Poor communication with other parties & 67.41 & 68.14 & 71.58 & 68.73 \\
\hline 15 & Unqualified Workforce & 64.44 & 69.60 & 70.53 & 67.89 \\
\hline 16 & Poor coordination with staff & 70.37 & 64.12 & 67.37 & 67.32 \\
\hline 17 & Poor skill development & 67.32 & 68.80 & 69.47 & 64.47 \\
\hline 18 & Poor cost controlling system & 66.67 & 68.14 & 64.21 & 66.48 \\
\hline 19 & Poor estimation practices & 65.93 & 56.81 & 68.42 & 65.92 \\
\hline 20 & Inefficiency in billing and collecting payments & 63.70 & 66.46 & 66.32 & 65.35 \\
\hline 21 & Insufficient safety precautions at site & 68.15 & 64.84 & 61.05 & 65.07 \\
\hline 22 & Fraudulent practices in the organisation & 56.30 & 64.22 & 70.53 & 62.82 \\
\hline 23 & Internal organisation problems & 65.93 & 56.81 & 61.05 & 61.41 \\
\hline 24 & Disputes with other parties & 57.78 & 67.23 & 56.84 & 60.85 \\
\hline
\end{tabular}

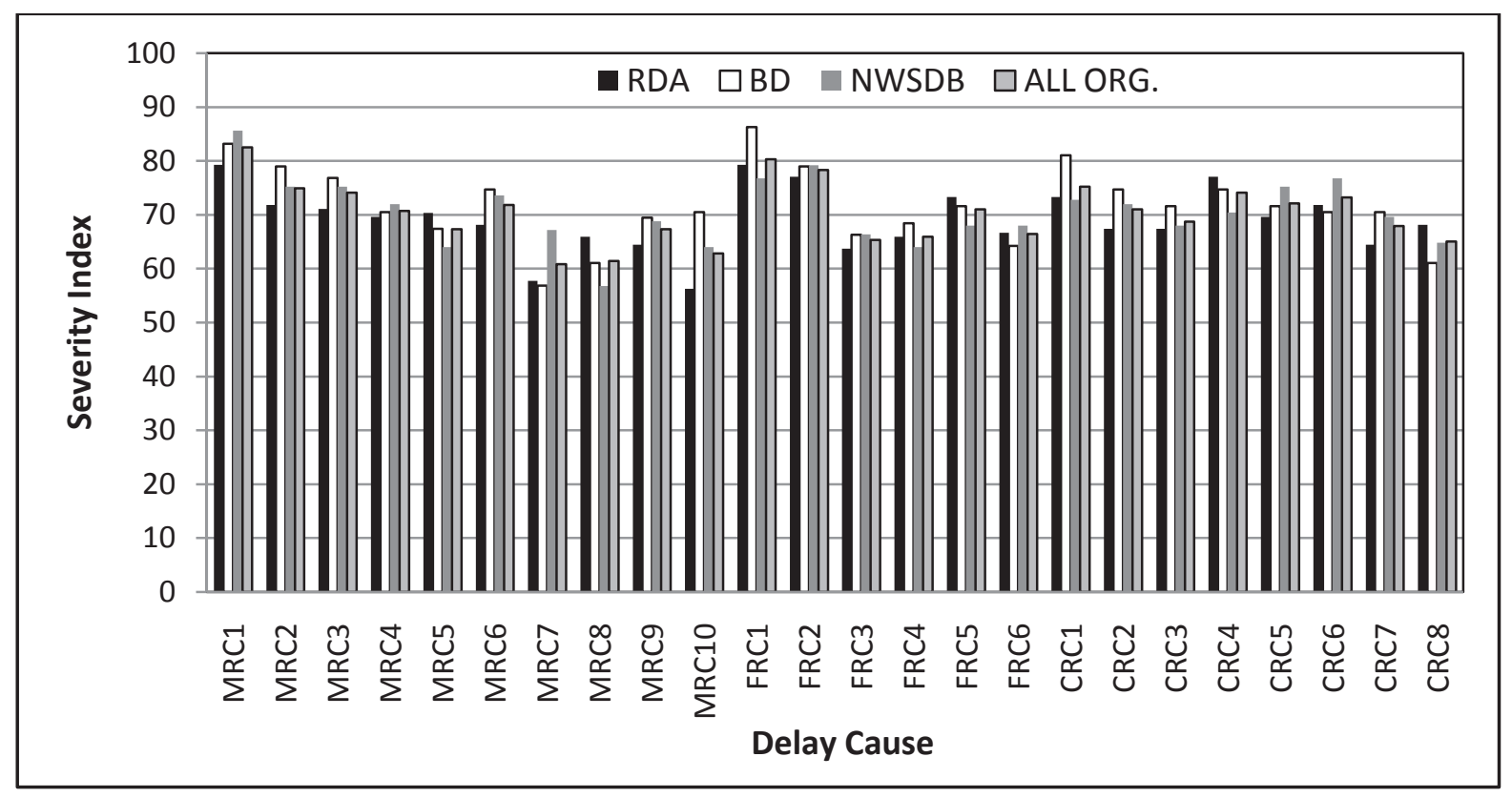

Figure 1 - Severity indices of causes of delay 


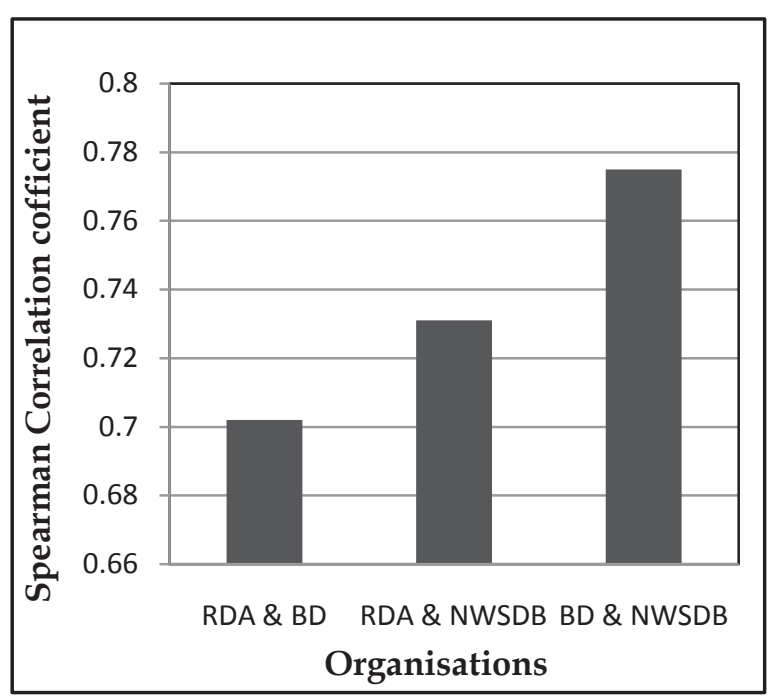

Figure 2 - Spearman rank correlation coefficient

those of the NWSDB and the BD in terms of geographic areas of operation, degree of heavy machinery usage and scope of work related to the projects. Therefore, the results of rank correlation are consistent with the perceptions expected of the respondents of these organisations on causes of delays attributable to the contractors.

\subsection{Mechanism of causes of delay and mitigative measures}

This study considered 24 significant construction causes of delay attributable to the contractor. Nevertheless, this paper analysed only the top ten causes with respect to mechanisms and mitigative measures. The mechanisms and mitigative measures for the ten causes of delay are presented below.

\subsubsection{Poor project planning and scheduling}

The contractor should implement the project activities in the proper sequence to complete the defined stages of the project within the stipulated time frame, with designated resources. Contractors often fail to come up with a practical and practical work program at the planning stage. Project delays occur mostly due to inadequate experience of the contractors with regard to project planning. Proper scheduling should ensure that projects do not encounter resource bottlenecks at any stage of the project implementation. The contractors are usually reluctant to update schedules on a regular basis.

Projects should be planned in such a way that much of the work is executed in the months of favourable weather since wet months are less suitable for construction work. Most of the time, resources in projects either become idle or go skimp, due to improper scheduling. Contractors should schedule the work in such a way that it facilitates the continuous and uninterrupted utilisation of their resources.

\subsubsection{Low profit margin}

Profit which is the reward for implementing a project is the amount of money realised after setting aside for the expenditure. Profit invariably depends on the risk and difficulties associated with the project execution. If the perceived risk and difficulties to be encountered in a project are high, a higher profit margin should be allocated. Besides the profit margin, which the contractor assigns to the bid determines his chances of securing the contract. Due to the increased number of contractors bidding for a single project, the margin of profit has squeezed as of late. The consequent resource problems and possible mistakes in execution of projects, could affect the profitability of projects. The government of Sri Lanka receives funds from donor countries for infrastructure development with conditions attached. One such condition is that the respective tender be awarded to a contractor from the donor country itself. Such tenders are always awarded at an exorbitantly high profit margin. Thereafter, the contractor who won the bid, negotiates with a few local contractors and subcontracts the work to the one who quoted the lowest price. Due to scarcity of work or in order to enhance cash flows, quite often they hardly keep a reasonable profit margin. In such case, the accurate estimation of project cost before bidding is of great importance to the contractor. The cost estimate of labour, construction equipment, materials, subcontracts, taxes, overheads, and surety bonds need to be calculated accurately and added to the mark-up to arrive at the final bid value. 


\subsubsection{Inadequate cash flow management} Inadequate cash flow management by the contractor could cause delays in the project. The availability of money on time is quite important for project success. If sufficient money for the project expenses is not available, the due payments will remain unsettled for a long time resulting in project delays. In these situations, businesses with high gearing are at a risk.

Some public sector organisations take an unduly long time to settle the progress payments due to the rigorous internal procedures that are involved. Delays in receiving payments for the work completed by the contractor, directly affect the completion period of the project. The contractor is able to receive the payments for 'material at site' and 'advance for material purchase' in the progress payment bill if it is stipulated in the contract documents.

\subsubsection{Handling of too many projects at a given time}

There are many factors a contractor should consider before determining the optimum number of projects that could handled concurrently, which are as follows; number of workers, availability of machinery and financial resources, management capability and the types of work. Both quality and progress of construction can become affected if a contractor undertakes more projects than their capacity permits. The resultant inadequate supervision invariably results in poor quality work and complaints from the consultant, followed by instructions to 'rework'. Main contractors mostly delegate works to subcontractors who may have a low motivation to perform the works as per the schedule and required quality. If a contractor undertakes too many projects, he will have to concomitantly increase the capacity of resources. The contractor has to deploy the available resources across all projects undertaken. The projects commenced later may not have sufficient resources left to continue uninterrupted. Inevitably, the contractor encounters the difficulty of executing all projects undertaken in parallel, and ultimately, none of the projects can be completed within the stipulated period. This is because, in the short run, it may not be possible to increase resources. Therefore, the contractor should undertake only a manageable number of projects, which is commensurate with the existing capacity.

\subsubsection{Incompetence of key staff}

Incompetence of key staff is one of the significant causes of construction delays. Some contractors are weak in project planning, implementation and controlling of site operations due to the incompetence of the key staff. Although contractors claim at the bidding stage to be having qualified project managers, they are unable to provide them once the project is in progress.

Effective project implementation requires the services of competent personnel. It will make the following tasks efficient and effective; supervision, decision making, work planning and coordination at the site. These are the attributes necessary to achieve successful project performance. Contractors should ensure that they have the right personnel with correct qualifications and relevant experience to manage the projects. The project managers must have experience and qualifications in construction management so that they can effectively utilise the latest project management tools. A typical project management problem that results from insufficient capacity of the key staff is the slow response to the issues that occur at sites; this will badly impact on the overall work progress.

\subsubsection{Poor decision making by management}

The decision to bid for a large construction project should not be taken until all significant factors have been considered in an objective and precise manner. This decision should be satisfactory from all view points. Allthe key members of the management staff should participate in making important decisions concerning updating and regulating the company policies.

\subsubsection{Insufficient quality control}

It is not uncommon in construction projects that completed work becomes rejected by consultants due to inferior quality. In such situations, the contractors are instructed to put it right at their own cost and time. Such 
situations could lead to disputes as to who should bear the additional cost of corrective work and the extra time taken. Delays caused due to adopting improper construction methods, supplying of inferior quality materials, improper testing methods and defective work are more crucial to the contractor than to the consultant. The contractors should be more committed to conformance to project specifications.

\subsubsection{Insufficient availability of equipment}

Use of equipment is very important to contractors because this could save time and money. Many of the contractors do not keep their construction equipment in good condition, so they may not be readily available for the construction work. When the construction projects undertaken are too many and too heavy, the number of equipment available to be engaged in the project may not be adequate. In this situation, the equipment could become defective due to overuse and not having sufficient time for maintenance.

Sometimes contractors do not use appropriate equipment in projects because either the appropriate equipment for the particular work is not available or too expensive to hire. In Sri Lanka, most of the foreign contractors complete projects on time and 'as planned' because they use appropriate machinery and equipment for the work.

The contractor must adopt a very effective maintenance program to minimise major breakdowns of equipment, thus avoiding big losses. Poor maintenance of equipment results in the increasing of downtime and the decreasing of the life time of the equipment.

\subsubsection{Poor supervision of work}

The quality of work can become inferior due to poor supervision at site. Since there is a direct relationship between construction output and the cost, the supervision of the former is vital. Due to poor supervision of construction work, it could become substandard or defective therefore it has a chance of being rejected. The development of the capacity of the supervisory staff through workshops and technical training is an essential consideration. Quality assurance, motivational programmes and site safety systems should be established to improve the productivity of construction projects.

\subsubsection{Delays in material supply}

Purchasing and supplying of materials in time is very important in construction because any delay in this could affect the work programme. Approval has to be sought in time from the consultant or client before purchasing certain materials.

Construction projects involve a series of dependent and interrelated activities which engage important resources such as money, manpower, machinery etc. If the crucial materials are not supplied in time, the respective activity cannot progress, causing delays in the dependant activities. This may also result in some machinery going idle, adding to the cost. The purchasing officer should follow the relevant procurement procedure to ensure materials are available at site, in time and in required quality and quantity. Some construction materials have to be imported from abroad. If there is any delay in importing these materials, it could cause delays in completing the project.

\section{Conclusions and Recommendations}

In this study, a significant attempt has been made to identify the important causes of delays attributable to the contractor and propose mitigative measures concerning the construction industry of Sri Lanka.

The study revealed that improper planning and scheduling of the contractor is the most significant delay factor among the 24 important causes of delay identified in this study.

Based on the findings of the study, the following recommendations can be made to mitigate the causes of delays attributable to the contractor with respect to major construction projects in Sri Lanka.

1 The contractor must prepare a realistic work programme in such a way that it is commensurate with his capacity and realistic duration. It means that 
scheduling should ensure that the project does not experience significant resource bottlenecks. It is essential that he holds progress review meetings regularly, involving all parties to ensure that the work progresses according to the schedule.

2. The contractor's bid value should be realistic. They must ensure that they have the financial strength, necessary resources and capabilities, to complete the project at the quoted tender sum.

3. The Contractor should use their financial resources effectively and manage the cash flows by utilising advanced payments and progress payments. The Contractor should also prepare the monthly payment documents in time.

4 The contractor must have a good assessment of their maximum capacity in terms of previous experience, availability and capacity of workers, machinery, management capability, and the size of their geographic operational area.

5. The contractor should recruit right personnel with the correct qualifications to manage their projects. The skills of applying project management techniques of the contractor's staff have to be updated to ensure that they are conversant with the latest techniques. The key personnel at the managerial level should be invited to participate with important decision making regarding the project execution and regulating the contractor's policies. The contractor's inside information should be kept in confidence at all times.

6. The contractor should conform to the specifications when supplying construction materials, service fittings and equipment etc.

7. The contractor should ensure that the appropriate machinery and equipment are available in time. They should adopt daily and periodic maintenance programs for the equipment, according to the manuals.
8. The contractor should improve their productivity, cost control systems, and quality of work through appropriate follow up action.

9. The contractor should develop human resources through proper technical training and recruiting qualified and experienced craftsmen.

10. The contractor should prepare an appropriate procurement plan for material purchasing in order to maintain the buffer stocks of material on site. They also should engage a material specialist conversant in contract specifications to decide on the type materials required for the project.

11. Since the contractors are usually more responsible for construction delays in a project, the Contractors Association of Sri Lanka must prepare Guidelines on mitigating construction delays.

\section{References}

1. Ahmed, S., Azher, S., Castillo, M., Kappagantula, P. "Construction Delays in Florida; An Empirical Study", 2003.

2. Al-Barak, A. A., "Causes of Contractor's failures in Saudi Arabia", Master thesis, CEM Dept., KFUPM. Dhahran, Saudi Arabia, 1993.

3. Al-Khalil, M., Al-Ghafly, M., "Important Causes of Delay in Public Utility Projects in Saudi Arabia", Construction Management and Economics, 1999;17(5):647-55.

4. Assaf, S. A., Al-Halil, M., Al-Hazmi, M., "Causes of Delay in large Building Construction Projects", Journal of Management in Engineering. ASCE1995, 45-50.

5. Assaf, S. A., Al-Hejji, S., "Causes of Delays in Large Construction Projects", International Journal of Project Management, 2006, 24(4), 349357.

6. Chan, D. W., Kumaraswamy, M. M., (1991), "Comparative Study of Causes of Time Overruns in Hong Kong Construction Projects", International Journal of Project Management, 1997,55-63. 
7. Chan, D. M., Kumaraswamy, M. M., "Contributors to Construction Delays", Construction Management and Economics (1998), 17-29.

8. Dolage, D. A. R., and Rathnamali, D. L. G., "Causes of Time Overrun in Construction Phase of Building Projects-A Case Study on Department of Engineering Services of Sabaragamuwa Provincial Council", EngineerJournal of Institution of Engineers Sri Lanka, XXXXV1 (03), 09-18.

9. Dolage, D. A. R. and Perera, P. W. S. (2009), "Delays in the Pre Construction Phase of State Sector Building Projects", Engineer-Journal of Institution of Engineers Sri Lanka, Vol. XXXXII (3), 2009, 22-30.

10. Jayawardene, A. K. W., Panditha, H. G. W., "Understanding and Mitigating the Factors Affecting Construction Delay", Engineer-Journal of Institution of Engineers Sri Lanka, XXXV1 (02), 2003, 07-14.

11. Jonathan, J. S., "Construction Delay Computation Method", Journal of Construction Engineering and Management Jan/Feb 2001, 6065.

12. Kumaraswamy, M. M., Chan, D. W., "Determinants of Construction Duration", Construction Management and Economics, 1995; 209-17.

13. Noulmanee, A., Wachirathamrojn, J., Tantichattanont, P., "Internal Causes of Delays in Highway Construction Projects in Thailand", July, 1999.

14. Pathiranage, Y. L., Halwatura, R. U., "Factors Influencing the duration of Road Construction Projects in Sri Lanka", Engineer-Journal of Institution of Engineers Sri Lanka, XXXXIII(04), 2010, 17-30.

15. Pradeep, S., "Delays in Construction Project and its Consequences", International Journal of Project management, 1999.

16. Sambasivan, M., Soon, Y. W., "Causes and Effects of Delays in Malaysian Construction Industry", International Journal of Project Management, 2006, 25, 517-526. 